\title{
$\mathrm{TiO}_{2}$ 필러를 포함하는 PEO/PMMA 고분자 복합체 전해질의 이온전도도 및 결정화도
}

\author{
이륜규* · 박수진** · 김 석*,† \\ *부산대학교 화공생명공학부 \\ 609-735 부산시 금정구 장전동 산 30 \\ **인하대학교 화학과 \\ 402-751 인천광역시 남구 인하로 100
}

(2011년 8월 16일 접수, 2011년 9월 12일 채택)

\section{Study on Ionic Conductivity and Crystallinity of PEO/PMMA Polymer Composite Electrolytes containing $\mathrm{TiO}_{2}$ Filler}

\author{
Lyungyu Lee*, Soo-Jin Park** and Seok Kim*,† \\ *Department of Chemical and Biochemical Engineering, Pusan National University \\ San 30, Jangjeon-dong, Geumjeong-gu, Busan 609-735, Korea \\ **Department of Chemistry, Inha University, 100, Inharo, Nam-gu, Incheon 402-751, Korea \\ (Received 16 August 2011; accepted 12 September 2011)
}

\begin{abstract}
요 약
본 연구에서는 poly(ethylene oxide) (PEO)와 poly(methyl methacrylate) (PMMA) 블렌드를 고분자 매트릭스(matrix) 로 사용하고, 가소제로propylene carbonate $(\mathrm{PC})$, 리튬염인 $\mathrm{LiClO}_{4}$, 그리고 서로 다른 함량의 세라믹 필러인 $\mathrm{TiO}_{2}$ 를 이 용하여 용액 캐스팅 (solution casting)법에 의해 고분자 복합체 전해질 필름을 제조하였다. 고분자 전해질의 결정화도와 이온전도도는 각각, $\mathrm{X}$ 선 회절분석기(XRD)와 $\mathrm{AC}$ 임피던스법을 통해 분석하였고, 표면 형태학(morphology)을 조사하기 위해 주사전자현미경(SEM)으로 고찰하였다. 그 결과, $\mathrm{TiO}_{2}$ 의 함량을 증가시킴으로써 $\mathrm{PEO}$ 의 결정화 영역이 감소하였 고, 이온전도도는 증가하였다. 특히 $\mathrm{TiO}_{2}$ 의 함량이 $15 \mathrm{wt} \%$ 일 때 가장 높은 이온전도도가 관찰된 반면, $15 \mathrm{wt} \%$ 이상 을 첨가한 경우, 이온전도도가 감소된 경향을 관찰할 수 있었다. 이는 표면 형태학를 통해 고분자와 필러간의 비혼합 성 혹은 필러응집에 의해 불균일적인 형태학이 나타남으로써 이온전도도가 감소하는 현상을 확인할 수 있었다.
\end{abstract}

\begin{abstract}
In this work, polymer composite electrolytes were prepared by a blend of poly(methyl methacrylate) (PMMA) and poly(ethylene oxide) (PEO) as a polymer matrix, propylene carbonate as a plasticizer, $\mathrm{LiClO}_{4}$ as a salt, and by containing a different content of $\mathrm{TiO}_{2}$, by using the solution casting method. The crystallinity and ionic conductivity of the polymer electrolytes was evaluated using X-ray diffraction(XRD) and AC impedance method, respectively. The morphology of composite electrolyte film was analyzed by SEM method. From the experimental results, by increasing the $\mathrm{TiO}_{2}$ content, crystallinity of $\mathrm{PEO}$ was reduced, and ionic conductivity was increased. In particular, the ionic conductivity was dependent on the content of $\mathrm{TiO}_{2}$ and showed the highest value $15 \mathrm{wt} \%$. However, when $\mathrm{TiO}_{2}$ content exceeds $15 \mathrm{wt} \%$, the ionic conductivity was decreased. According to the surface morphology, the ionic conductivity was decreased because the polymer composite electrolytes showed a heterogenous morphology of fillers due to immiscibility or aggregation of the filler within the polymer matrix.
\end{abstract}

Key words: Ionic Conductivity, Polymer Composite Electrolytes, PEO, PMMA, Titanium Oxide

\section{1. 서 론}

이차전지는 전기를 저장하는 도구로서 반도체, 디스플레이와 함께 세계 정보기술산업(IT)을 이끌어 나갈 핵심 전략제품 중 하나로, 현 재는 인류의 생활과 밀접한 휴대용 전자 기기들의 성능을 좌우함은

\footnotetext{
${ }^{\dagger}$ To whom correspondence should be addressed.

E-mail: seokkim@pusan.ac.kr
}

물론 전기자동차의 동력원과 신재생 에너지의 전력저장 장치로서 그 필요성을 더해가고 있다[1,2]. 이러한 이차전지 산업에서 리튬계 이 차전지는 고가이지만 경량에 고에너지 밀도를 보유한 소형 전원이란 장점을 가지고 있어서 가장 큰 주목을 받고 있으며, 그 수요가 점차 증가하고 있다. 하지만 이러한 장점이 있는 반면, 금속리틈 전극이 액체 전해질에 접촉하는 경우 발생하는 문제로서, 화재와 폭발을 일 으킬 수 있기 때문에 상용화된 리튬계 이차전지에서 가장 중요시 되 
고 있는 항목은, 금속리튬 음극을 사용하는 경우 안전성을 확보할 수 있는 완전 고체형 고분자 전해질을 개발하는 것이다. 이러한 완전 고 체형 고분자 전해질을 기반으로 한 리튬계 이차전지의 개발은 에너 지 밀도의 향상, 전지의 안전성 증대, 전해액 누출의 방지 등 전지의 신뢰성을 향상시킬 수 있으며, 박형의 전지 제작이 용이하다는 장점 이 있어 소형 이차 전지와 더불어 전기 자동차용의 고용량 이차전지 등에 적용될 수 있는 차세대 전지로 각광을 받고 있다[3-6].

고체 고분자전해질은 액체전해질 및 무기전해질과 비교하여 안정 성 및 유연성을 가지기 때문에 많은 이점을 갖고 있다[7-10]. 고체 고 분자 전해질 개발에 poly(ethylene oxide) (PEO)를 포함하는 연구가 주류를 이루고 있는데 이는 전하-운반체 이온을 발생시키도록 무기 염과 착물을 형성할 수 있는 극성기를 포함하고 전하-운반체 이온의 이동이 용이한 낮은 유리전이온도를 가지기 때문이다. $\mathrm{PEO}$ 를 기본 으로 하는 고분자와 리튬염이 착물을 형성하는 이러한 형태의 충 전지는 박막의 형태로 제작이 가능하고 높은 에너지 밀도를 가지 는 반면, 상온에서 낮은 이온 전도도를 가진다는 문제점이 있다. 이 문제점을 보완하면 다른 전해질보다 우수하고 실용성이 있는 것으 로 사료된다. 현재 연구되어지는 고체 고분자전해질은 크게 두 가 지로 분류할 수 있는데, poly(ethylene oxide)를 기본 소재로 하여 다른 고분자를 블렌딩하는 것과 새로운 고분자 시스템을 개발하는 것이다. 고분자량의 $\mathrm{PEO}$ 를 이용하면 고체 전해질의 기계적 특성 은 증가하나, 리틈염과의 복합체를 제조할 경우 결정성의 복합체 가 형성되어 고체 고분자전해질로서의 역할을 하지 못한다. 그러 나 저분자량의 $\mathrm{PEO}$ 를 사용할 경우 이온전도도가 좋은 반면에 고 체 전해질의 역할을 하기에는 기계적 특성이 부족하기 때문에 향 상시킬 필요가 있다[11-14].

이러한 문제점을 해결하기 위한 방법에는 결정성이 없는 고분자 와 블렌드 하는 방법으로 본 실험에서 사용한 PMMA[15,16]와 같 은 아크릴레이트계와 고분자량의 $\mathrm{PEO}$ 를 블렌드하여 이온전도도 를 조사한 예에서는 $30^{\circ} \mathrm{C}$ 에서 $10^{-4} \sim 10^{-5} \mathrm{~S} / \mathrm{cm}$ 정도의 이온전도도 를 나타낸 것이 보고되었다[17]. 또 다른 방법으로, 비정질의 고분 자 주사슬에 저분자량의 ethylene oxide 곁가지를 결합하여 결정 화도를 낮추어 이온전도도를 증가시키는 방법 $[18,19]$, 망상 구조를 가지는 고분자에 분자량이 낮은 $\mathrm{PEO}$ 를 고정화시켜 전도도를 향상 시키는 방법[20]이 있고, 세라믹 파우더와 $\mathrm{Al}_{2} \mathrm{O}_{3}$ [21,22], $\mathrm{TiO}_{2}$ $[23,24], \mathrm{SiO}_{2}$ 등의 무기 산화물 첨가 및 액상의 가소제의 첨가로 고분자 주 사슬의 유연성을 증가시키는 방법 $[25,26]$ 등이 현재 활 발히 연구되고 있다.

본 연구에서는 결정화도에 따른 이온전도도의 변화를 고찰하기 위 하여, 기존의 연구자들과는 달리 고분자 지지체로 상온에서 우수한 이온전도도와 넓은 포텐셜 범위에서 높은 안정성을 나타내는 PEO 와 PMMA의 고분자 매트릭스[27]에 염으로 옥사이드계 고분자인 $\mathrm{PEO}$ 와 배위결합에 의한 착체물 형성이 가능한 $\mathrm{LiClO}_{4}$ 를 사용하고, 고유전율의 카보네이트 화합물로써 $\mathrm{PC}$ 를 첨가하였으며, $\mathrm{PEO}$ 의 높 은 결정성을 낮추기 위해 이온 전도특성에 유리한 무정형 영역의 상 대적인 부피 분율을 증가시킬 수 있는 세라믹 필러로, 산화력이 커 서 광촉매로 활용도가 높은 $\mathrm{TiO}_{2}$ 를 사용하여 고분자 전해질을 제조 하였다. 그리고 $\mathrm{TiO}_{2}$ 의 첨가량에 따른 결정화도 및 형태학의 변화를 관찰하기 위해 $\mathrm{X}$ 선 회절분석기와 주사전자현미경을 통해 확인하였 고, 이들 고분자전해질을 사용한 단위셀을 제작하여 전기화학적 특 성에 미치는 영향을 고찰하였다.

\section{2. 실 험}

\section{2-1. 재료}

본 연구에서 사용된 고분자 전해질의 구성재료는 $\mathrm{PEO}\left(\mathrm{M}_{w}=1.0 \times\right.$ $10^{5}$, Aldrich), $\operatorname{PMMA}\left(\mathrm{M}_{w}=1.2 \times 10^{5}\right.$, Aldrich), propylene carbonate ( $\mathrm{PC}$, Junsei)를 추가적인 처리 없이 사용하였으며, $\mathrm{TiO}_{2}$ 는 Aldrich에 서 구입하였고, 유기용매로 사용된 acetonitrile(ACN)은 Junsei Chemical(Japan)에서 구입하여 사용하였다. 또한 리튬염으로 사용한 lithium perchlorate $\left(\mathrm{LiClO}_{4}\right.$, battery grade, Aldrich)는 추가처리 없이 사용하였다.

\section{2-2. 고분자 전해질의 제조}

$\mathrm{PEO}$ 와 PMMA 고분자를 아세토니트릴에 용해한 후 여기에 $\mathrm{PC}$ 를 첨가하여 $\mathrm{PEO} / \mathrm{PMMA}$ 고분자 매트릭스와 $\mathrm{PC}$ 가 완전히 혼합될 수 있 도록 3시간 동안 교반을 시행하였고, 이때 사용한 $\mathrm{PC}$ 와 $\mathrm{PEO}$ 는 0.1:1 의 비율로 가하여 사용하였다. $\mathrm{PEO/PMMA} \mathrm{고분자} \mathrm{매트릭스와} \mathrm{PC}$ 가 완전히 혼합된 용액에 $\mathrm{LiClO}_{4}$ 를 $\mathrm{PEO}$ 와 1:16의 비율로 혼합하여 상온에 2시간 동안 교반시켰다. 이어서 일정량의 아세토니트릴에 $\mathrm{PEO}$ 고분자의 기준 중량에 대비 $0,5,10,15,20 \mathrm{wt} \%$ 의 $\mathrm{TiO}_{2}$ 를 각 각 첨가하여 10 분간 소니케이션(sonication)을 시킨 뒤 앞서 제조한 혼합용액에 각각 투입하여 추가로 1 시간 동안 교반한 후 이를 $50{ }^{\circ} \mathrm{C}$ 의 진공 오븐에서 24 시간 동안 건조하여 고분자 복합체 전해질 (polymer composite electrolytes, PCE) 필름을 제조하였다. 고체 고 분자 전해질의 제조공정은 Fig. 1에 나타내었다.

\section{2-3. 고분자 전해질의 결정화도 및 표면구조}

$\mathrm{PEO} / \mathrm{PMMA}$ 고분자 매트릭스에 $\mathrm{PC}, \mathrm{LiClO}_{4}$, 그리고 $\mathrm{TiO}_{2}$ 의 첨가 에 따른 복합체 전해질의 결정화도의 변화를 살펴보기 위해 $\mathrm{X}$ 선 회 절분석기(XRD PHILIPS, X' pert PRO MRD)를 사용하였고, 또한 복합체 전해질의 표면 형태학은 주사전자현미경(SEM: HITACHI $\mathrm{S} 3500 \mathrm{~N})$ 을 이용하여 관찰하였다.

\section{2-4. 전기화학적 특성}

제조된 복합체 전해질의 이온전도도를 측정하기 위해 교류 임피

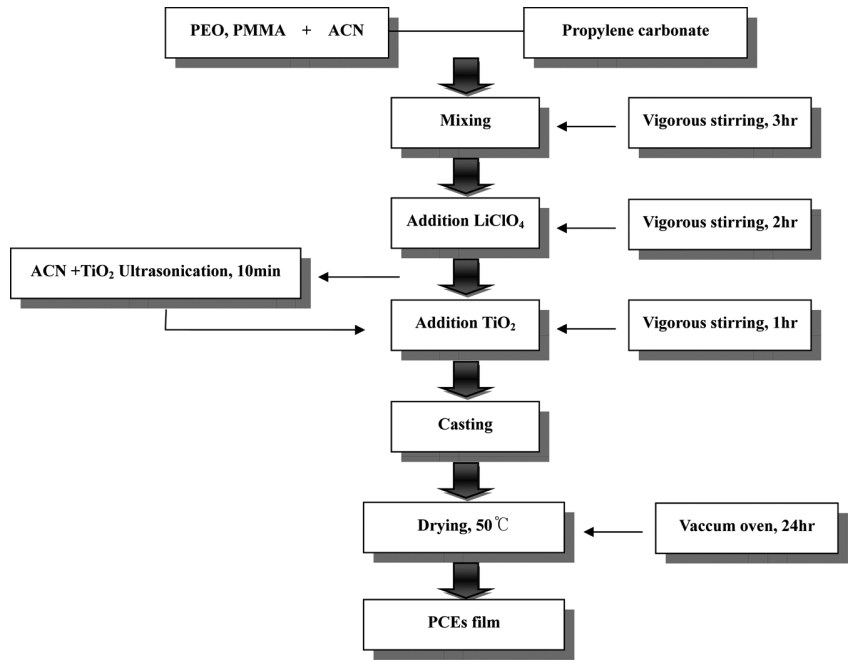

Fig. 1. Manufacturing process of polymer composite electrolytes (PCE).

Korean Chem. Eng. Res., Vol. 49, No. 6, December, 2011 
던스(ac impedance) 측정기 IVIUM STAT(Ivium Technologies, Netherlands) 를 사용하여 두 개의 스테인레스 스틸(stainless steel) 전 극에 전해질 막을 샌드위치 모양의 형태로 제조하여 $10 \mathrm{~Hz} 200 \mathrm{kHz}$ 의 주파수 범위, 상온에서 벌크저항(bulk resistance $\left(\mathrm{R}_{b}\right)$ )을 측정하여 이온전도도의 값을 계산할 수 있었다.

\section{3. 결과 및 고찰}

\section{3-1. 복합체 전해질의 결정화도}

$\mathrm{XRD}$ 는 $\mathrm{X}$ 선을 결정에 부딪히게 하면 그 중 일부는 회절을 일으키 고 그 회절각과 강도는 물질 구조상 고유한 것으로 이 회절 X선을 이용하여 고분자 전해질에 함유된 결정성 물질의 종류와 양에 관 계되는 정보를 알 수 있는 측정 방법 중의 하나로, Fig. 2는 $\mathrm{TiO}_{2}$ 의 첨가에 따른 $\mathrm{PEO} / \mathrm{PMMA}$ 고분자 복합체의 결정화도 변화를 관 찰하기 위해 나타낸 $\mathrm{XRD}$ 의 분석 결과이다. 주로 $\mathrm{PEO}$ 의 결정화 영역은 $2 \theta$ 의 $20 \sim 30^{\circ}$ 의 영역에서 관찰할 수 있었고, 무기필러인 $\mathrm{TiO}_{2}$ 를 첨가함에 따라 결정화 영역이 감소함을 확인할 수 있었다. Fig. 2의 결과에서 관찰된 바와 같이, 결정화 영역과 비정질 영역 이 공존하는 반결정 고분자인 $\mathrm{PEO}$ 가 반응성이 강한 아크릴계 고 분자인 PMMA와 무기필러인 $\mathrm{TiO}_{2}$ 로 합쳐짐에 따라 $\mathrm{PEO}$ 에서 분 자 사슬간에 작용하는 분자간 상호작용으로 결정화 영역의 성장을 억제하고, 이로 인해 피크강도(intensity)의 감소, 즉 결정화도가 감 소되는 결과를 이끌어 내는 것으로 판단된다[28]. 고분자 전해질의 박막의 경우에 상대적 결정화도(relative crystallinity)는 피크강도 (peak intensity)의 비로써 계산할 수 있으며, 그 식은 다음 (1)과 같 이 계산된다[29].

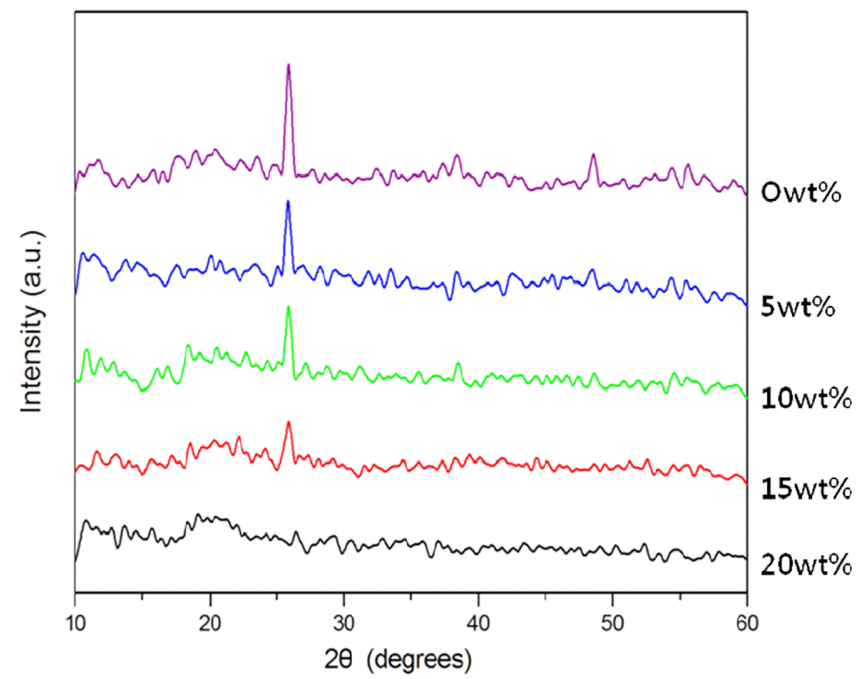

Fig. 2. X-ray diffraction patterns of PCEs with the different content of $\mathrm{TiO}_{2}$.

$$
\mathrm{X}_{C}=\frac{\mathrm{I}_{C}}{\mathrm{I}_{C}+\mathrm{I}_{A}} \times 100(\%)
$$

여기서, $\mathrm{X}_{C}$ 는 상대적 결정화도(relative crystallinity), $\mathrm{I}_{C}$ 는 peak intensity of crystalline reflections, 그리고 $\mathrm{I}_{A}$ 는 peak intensity of amorphous reflections을 의미한다. 가소제만 첨가된 PEO/PMMA 고분자 전해질의 결정화도는 $77.9 \%$ 로 나타났다. 가소제와 세라믹 필러인 $\mathrm{TiO}_{2}$ 가 모두 첨가된 고분자 전해질의 결정화도는 Table 1 에 정리하였다. 또한, 필러양에 따른 결정화도의 거동을 알아 보기 위 해 이를 Fig. 3에 그래프로 표시하였다. 그래프 거동을 분석하면, 필 러양을 증가함에 따라, 비례적으로 감소하는 것으로 나타났다. 특히, 필러를 $20 \%$ 까지 첨가한 복합체 전해질의 경우에는, 상대적 결정화 도가 약 $50 \%$ 까지 감소하는 것을 관찰할 수 있었다. 이 같은 사실로 미루어 세라믹 필러는 $\mathrm{PEO}$ 의 결정화도 감소에 결정적인 역할을 하 여 리튬이온이 전도될 수 있는 근본적인 상(phase)인 비정질상의 확 대를 마련하는 것으로 보이며 가소제는 결정화 감소효과보다는 고 분자 분자사슬 운동을 원활히 추진시켜 리튬이온이 잘 전도될 수 있 도록 보조 역할을 하는 것으로 사료된다.

\section{3-2. 복합체 전해질의 표면 형태학}

복합체 전해질의 표면 형태학을 관찰하기 위해 주사전자현미경 (SEM)을 이용하여 세라믹 필러의 함량에 따른 고분자 전해질의 변 화를 Fig. 4 를 통해 확인할 수 있었다. $\mathrm{TiO}_{2}$ 의 함량이 $0,5,10,15$, $20 \mathrm{wt} \%$ 로 변화함에 따른 형태학 변화가 관찰되었다. $\mathrm{TiO}_{2}$ 의 함량이 $0 \mathrm{wt} \%$ 의 고분자 전해질에서는 명확한 상 분리 현상이 없이 대체적 으로 균일한(homogeneous) 상을 보이고 있다가, $\mathrm{TiO}_{2}$ 의 성분 함량이

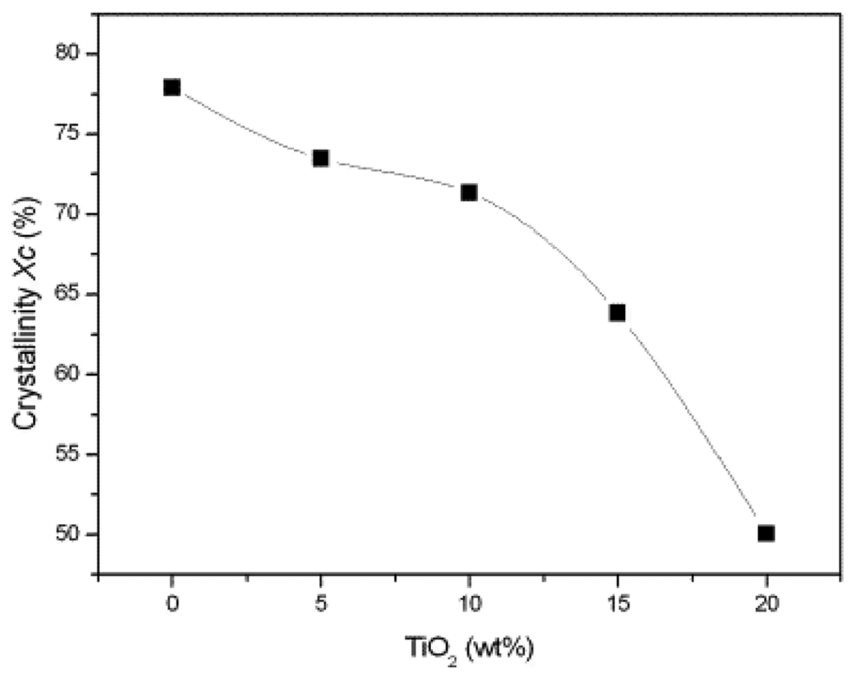

Fig. 3. Relative crystallinity (Xc) of PCEs with the different content of $\mathrm{TiO}_{2}$.

Table 1. Relative crystallinity for PEO/PMMA polymer composite electrolytes (PCE)

\begin{tabular}{cccccc}
\hline \hline Sample & Blend Ratio & $\begin{array}{c}\text { PEO/LiClO } \\
\text { (mass ratio) }\end{array}$ & $\begin{array}{c}\text { PEO/PC } \\
\text { (mass ratio) }\end{array}$ & $\begin{array}{c}\mathrm{TiO}_{2} \\
\text { (wt\%) }\end{array}$ & Relative crystallinity (\%) \\
\cline { 2 - 3 } PCE 1 & PEO / PMMA (wt.\%/wt.\%) & $16 / 1$ & $1 / 0.1$ & 0 & 77.9 \\
PCE 2 & $80 / 20$ & $16 / 1$ & $1 / 0.1$ & 5 & 73.5 \\
PCE 3 & $80 / 20$ & $16 / 1$ & $1 / 0.1$ & 10 & 71.3 \\
PCE 4 & $80 / 20$ & $16 / 1$ & $1 / 0.1$ & 15 & 63.8 \\
PCE 5 & $80 / 20$ & $16 / 1$ & $1 / 0.1$ & 20 & 50.1 \\
\hline
\end{tabular}

Korean Chem. Eng. Res., Vol. 49, No. 6, December, 2011 


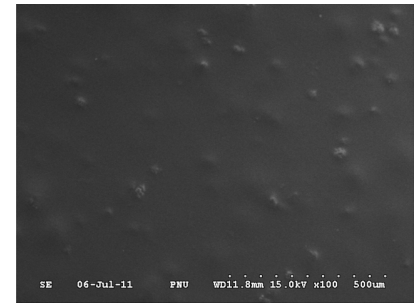

(a)

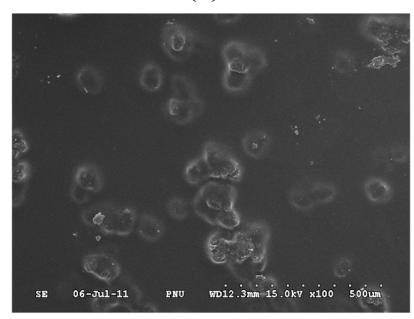

(c)

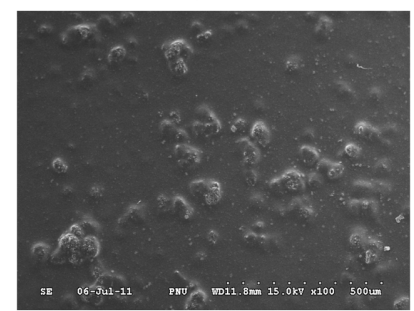

(e)

Fig. 4. SEM Photographs of containing (a) o, (b) 5, (c) 10, (d) 15, and (e) $20 \mathrm{wt} \% \mathrm{TiO}_{2} \mathrm{PEO} / \mathrm{PMMA}$ polymer electrolytes.

$15 \mathrm{wt} \%$ 까지 증가함에 따라 고분자 매트릭스 내의 무기 필러(filler) 의 함량이 증가하여 필러 입자의 분포가 증가하는 모습을 관찰할 수 있었는데, 이는 $\mathrm{TiO}_{2}$ 에 의해 복합체 전해질의 비정질(amorphous) 영 역의 확대를 가져와 리튬 이온의 운반율(transport)이 증가하여 이온 전도도가 향상될 수 있는 구조를 가지게 된 것이다. 하지만, $20 \mathrm{wt} \%$ 에서는 과다하게 필러 입자의 응집에 의해 불균일한(heterogeneous) 형태학을 관찰할 수 있었는데, 이는 $\mathrm{TiO}_{2}$ 의 과다한 분포로 인하여 리 튬이온이 비정질 영역을 통해서 전달될 수 있는 통로가 원활하지 못 함으로 인해 운반율을 저하시켜 리튬이온의 고립화(isolation) 현상 을 발생시킨 것으로 예상된다[30].

\section{3-3. 복합체 전해질의 이온전도도}

$\mathrm{TiO}_{2}$ 의 첨가에 따른 복합체 전해질의 이온전도도 변화를 관찰하 기 위해 임피던스 저항을 측정하였다. $\mathrm{TiO}_{2}$ 의 함량이 증가함에 따라 상온에서의 벌크상의 저항 $\left(\mathrm{R}_{b}\right)$ 을 구할 수 있는 임피던스 그래프를 Fig. 5에 나타내었다. 벌크상의 저항 $\left(\mathrm{R}_{b}\right)$ 은 비록 완전하지 못한 모양 이지만, 반원(semi-circle)의 크기와 비례하는 특징을 가지고 있다. 따 라서, $\mathrm{x}$ 축과 접하는 반원 크기가 작아질수록 저항 수치가 작아짐을 예 측할 수 있다. 보다 정확한 벌크상의 저항 $\left(\mathrm{R}_{b}\right)$ 은 $\mathrm{AC}$ 임피던스법을 통 해 측정하였으며, 전도도 $(\sigma)$ 는 다음 식 (2)을 이용하여 구할 수 있다.

$$
\frac{1}{\sigma}=\frac{\mathrm{R}_{b} \mathrm{~A}}{\mathrm{t}}
$$

여기서, $\mathrm{t}$ 는 고분자 전해질의 두께 그리고 $\mathrm{A}$ 는 고분자 전해질의 면 적을 의미한다.

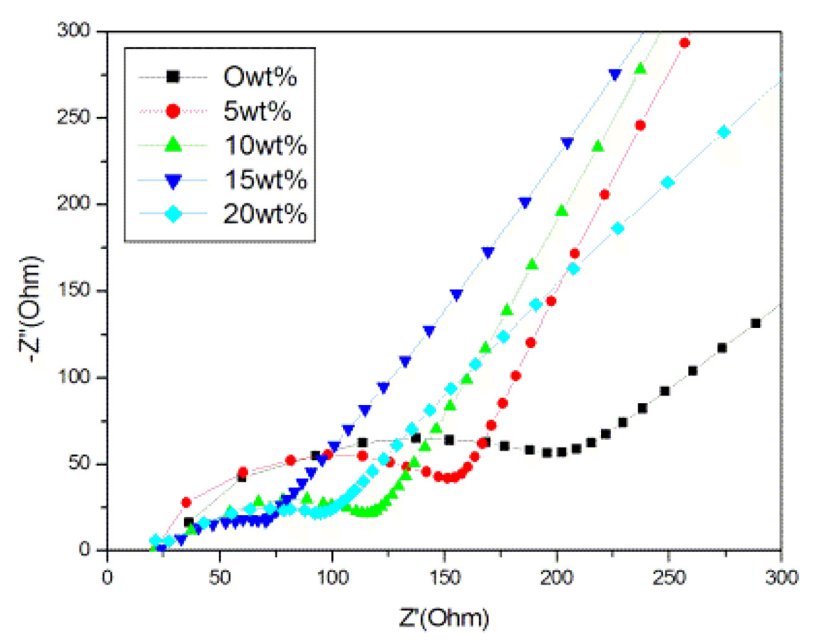

Fig. 5. Impedance plots of the PCEs containing a different content of $\mathrm{TiO}_{2}$.

벌크상의 저항 $\left(\mathrm{R}_{b}\right)$ 은 $\mathrm{TiO}_{2}$ 를 포함하지 않은 $\mathrm{PEO} / \mathrm{PMMA}$ 고분자 전해질보다 $\mathrm{TiO}_{2}$ 를 첨가한 고분자 전해질이 감소하고, $15 \mathrm{wt} \%$ 첨가 하였을 때 가장 큰 감소를 보였다. 이러한 벌크상의 저항 $\left(\mathrm{R}_{b}\right)$ 의 감소 는 $\mathrm{PEO}$ 사슬에 비정질의 $\mathrm{PMMA}$ 와 세라믹 필러인 $\mathrm{TiO}_{2}$ 를 첨가함으 로써 PEO 분자사슬간의 상호작용 감소 등과 같은 전반적인 고분자 의 구조에 영향을 미쳐 복합체 전해질의 결정화도가 감소하였기 때 문으로 판단된다[31,32].

$\mathrm{TiO}_{2}$ 의 첨가에 따른 이온전도도의 증가된 현상은 Fig. 6에서 확인 할 수 있는 바와 같이 $\mathrm{TiO}_{2}$ 의 첨가량이 증가할수록 높은 이온전도도 를 나타내었고, 특히 $15 \mathrm{wt} \%$ 에서 $1.14 \times 10^{-4} \mathrm{~S} / \mathrm{cm}$ 의 가장 높은 이온 전도도를 나타내었다. 이러한 이온전도도의 변화는 $\mathrm{TiO}_{2}$ 의 첨가량이 증가할수록 $\mathrm{PEO}$ 고분자 매트릭스의 비정질 영역이 증가하여 고분자 사슬의 유동성이 증가하고, 그 결과 동력학적으로 이온의 해리 및 이 동현상이 쉽게 일어나기 때문이다[33,34]. 따라서 Fig. 6에서 보는 바 와 같이 $\mathrm{TiO}_{2}$ 의 함량비에 따른 평균 이온 전도도는 대체적으로 비례 하는 결과를 보인다. 하지만 $20 \mathrm{wt} \%$ 의 $\mathrm{TiO}_{2}$ 를 포함하는 필름은 $15 \mathrm{wt} \%$ 의 필름보다 줄어든 $0.87 \times 10^{-4} \mathrm{~S} / \mathrm{cm}$ 의 이온전도도 값을 보이 는데, 이는 $\mathrm{TiO}_{2}$ 함량비가 과다하게 증가함으로써 $\mathrm{TiO}_{2}$ 가 고분자 사

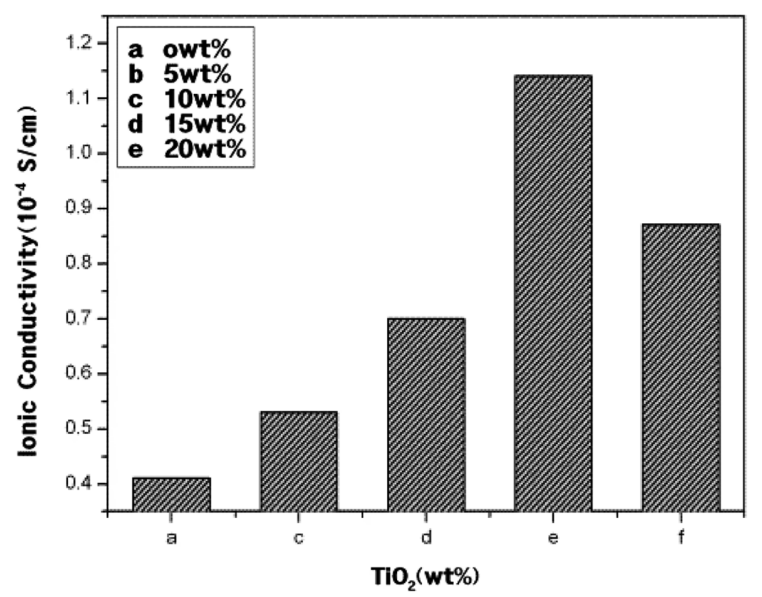

Fig. 6. Room temperature ionic conductivity of PCEs containing a different content of $\mathrm{TiO}_{2}$.

Korean Chem. Eng. Res., Vol. 49, No. 6, December, 2011 
슬을 통한 리튬이온의 이동에 방해작용을 일으킨 것으로 판단된다. 이는 Fig. 4(e)의 SEM 표면분석결과에서 알 수 있듯이, 상분리 (phase separation) 현상이 발생하여, 이온이 전달될 수 있는 비정질 영역이 고립화(isolation)되는 현상에 의해 이온전도도가 감소한 것 으로 생각할 수 있다.

\section{4. 결 론}

본 연구에서는 $\mathrm{TiO}_{2}$ 필러의 함량변화에 따른 고체 고분자 전해질 의 결정화도 및 이온전도도 변화를 고찰하기 위하여, $\mathrm{PEO/PMMA}$ 고분자 매트릭스에 리튬염과, 가소제, $\mathrm{TiO}_{2}$ 를 첨가한 고분자 복합체 전해질 필름을 제조하여 이를 $\mathrm{XRD}, \mathrm{SEM}, \mathrm{AC}$ 임피던스법 등을 이 용하여 확인하였다. 그 결과 제조한 복합체 전해질은 $\mathrm{TiO}_{2}$ 의 함량이 증가할수록 비정질 영역이 증가하였다. 이는 $\mathrm{PEO}$ 의 고분자 사슬의 결정화를 감소시켜 이온전도도가 증가하고 $15 \mathrm{wt} \%$ 의 $\mathrm{TiO}_{2}$ 가 첨가 된 복합체 전해질이 실온에서 $1.14 \times 10^{-4} \mathrm{~S} / \mathrm{cm}$ 의 가장 높은 이온전도 도를 보였다. 하지만, $\mathrm{TiO}_{2}$ 의 함량이 $15 \mathrm{wt} \%$ 이상인 경우, 이온전도 도는 감소하였다. 즉, $\mathrm{TiO}_{2}$ 함량이 $15 \mathrm{wt} \%$ 이상으로 증가하여 결정 화도가 추가적으로 감소하여도, 이온전도도가 증가하지 않고, 감소 하는 경향을 보였다. 이러한 현상은 $15 \mathrm{wt} \%$ 이상으로 $\mathrm{TiO}_{2}$ 를 도입 하는 경우, SEM 분석결과에서 확인할 수 있는 바와 같이, 이성분 고 분자와 세라믹 필러간에 상분리 및 필러 응집에 의해 불균일한 형태 학과 관련이 있다고 생각된다. 복합체 전해질의 이온전도도는 $\mathrm{TiO}_{2}$ 의 첨가량 증가에 따라 일정 부분까지 증가하지만, 첨가량이 너무 높 은 경우, 상분리와 관련하여 균일하지 못한 고분자 전해질 형태학을 갖게 되어서, 리튬 이온의 운반율 저하로 인해 전도도가 감소하는 것 으로 판단된다.

\section{감 사}

이 논문은 2011년도 정부(교육과학기술부)의 재원으로 한국연구 재단의 지원을 받아 수행된 기초연구사업입니다(과제번호: Grant No.: 2011-0009007).

\section{참고문헌}

1. Schalkwijk, W. A. V. and Scrosati, B., Advances in Lithium Ion Batteries, Kluwer Academic, New York, 2002.

2. Nazri, G. A. and Pistoia, G., Lithium Batteries, Kluwer Academic, New York, 2004.

3. Moon, T., Kim, C. J. and Park, B. W., "Electrochemical Performance of Amorphous-silicon Thin Films for Lithium Rechargeable Batteries,' J. Power Sources, 155, 391-394(2006).

4. Dias, F. B., Plomp, L. and Veldhuis Jakobert, B. J., "Trends in Polymer Electrolytes for Secondary Lithium Batteries,' J. Power Sources, 88, 169-191(2000).

5. Meyer, W. H., "Polymer Electrolytes for Lithium-ion Batteries," Adv. Mater, 10, 439-448(1998).

6. Song, J. Y., Wang, Y. Y. and Wan, C. C., "Review of Gel-type Polymer Electrolytes for Lithium-ion Batteries,' J. Power Sources, 77, 183-197(1999).

7. Fergus, J. W., "Ceramic and Polymeric Solid Electrolytes for Lithium-ion Batteries,' J. Power Sources, 195, $4554-4569$ (2010).
8. Shanmukaraj, D., Wang, G. X., Murugan, R. and Liu, H. K., "Ionic Conductivity and Electrochemical Stability of Poly(methylmethacrylate)-poly(ethylene oxide)blend-ceramic Fillers Composites,' J. Phys. Chem. Solids, 69, 243-248(2008).

9. Kim, S., Hwang, E. J., Lee, S. G., Lee, J. R. and Park, S. J., "Preparation and Electrochemical Properties of Polymeric Composite Electrolytes Containing Organic Clay Materials,' Polymer(Korea), 31(4), 297-301(2007)

10. Kim, S., Han, A. R., Park, S. J. and Shin, J. S., "Preparation and Electrochemical Behaviors of Polymer Electrolyte Based on PEO/PMMA Containing Li Ion,' Korean Chem. Eng. Res. (HWAHAK KONGHAK), 47(4), 476-480(2009).

11. Shriver, D. F., Papke, B. L., Ratner, M.A., Dupon, R., Wong, T. and Brodwin, M., "Structure and Ion Transport in Polymer-salt Complexes,' Solid State Ionics, 5, 83-88(1981).

12. Yasuo, T., Kazuo, H. and Yasuhiko, S., "Ionic Conductivities of Hybrid Films Composed of Comb Polymers Containing Esters as Pendant Groups and Lithium Trifluoromethane Sulfonate, Solid State Ionics, 60, 125-130(1993).

13. Armand, M. B., "Polymer Electrolytes,' Ann. Rev. Mater. Sci, 16, 245-261(1986).

14. Wright, P. V., "Electrical Conductivity in Ionic Complexes of

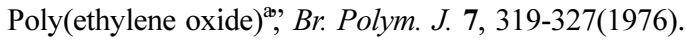

15. Bohnke, O., Frand, G., Rezrazi, M., Rousselot, C. and Truche, C., "Fast Ion Transport in New Lithium Electrolytes Gelled with PMMA. 2. Influence of Lithium Salt Concentration,' Solid State Ion., 66(1-2), 105-112(1993).

16. Christie, A. M. and Vincent, C. A., "The $\mathrm{Li} / \mathrm{Li}^{+}$Couple in Propylene Carbonate Electrolytes and Poly(methyl methacrylate) gels,' J. Appl. Electrochem., 26(3), 255-267(1996).

17. Borkowska, R., Laskowski, J., Plocharski, J., Przyluski, J. and Wieczorek, W., "Performance of Acrylate-poly(ethylene oxide) Polymer Electrolytes in Lithium Batteries,' J. Appl. Electrochem., 23, 991-995(1993).

18. Gao, L. and McDonald, D. D., "Characterization of Irreversible Processes at the Li/poly[bis(2,3-di-(2-methoxyethoxy)propoxy)phosphazene] Interface on Charge Cycling,', J. Electrochem. Soc., 144(4), 1174-1179(1997).

19. Rietman, E. A. and Kaplan, M. L., "Single-ion Conductivity in Comblike Polymers,' J. Polym. Sci., Part C: Polym. Lett., 28(6), 187-191(1990).

20. Fang, C. P. and Ying, S. K., "Structure and Ionic Conductivity of Graft Polyester Networks Containing Lithium Perchlorate,' Eur. Polym. J., 29(6), 799-803(1993).

21. Croce, F., Appetechi, G. B., Persi, L. and Scrosati, B., "Nanocomposite Polymer Electrolytes for Lithium Batteries,' Nature, 394, 456-458(1998).

22. Krejza, O., Velická, J., Sedlaříková, M. and Vondrák, J., "The Presence of Nanostructured $\mathrm{Al}_{2} \mathrm{O}_{3}$ in PMMA-based Gel Electrolytes,' J. Power Sources, 178(2), 774-778(2008).

22. Kumar, B. and Scanlon, L. G., "Polymer-ceramic Composite Electrolytes: Conductivity and Thermal History Effects", Solid State Ion., 124(3-4), 239-254(1999).

23. Jeon, J. D., Kim, M. J. and Kwak, S. Y., "Effects of Addition of $\mathrm{TiO}_{2}$ Nanoparticles on Mechanical Properties and Ionic Conductivity of Solvent-free Polymer Electrolytes Based on Porous P (VdF-HFP)/P(EO-EC) Membranes,' J. Power Sources, 162(2), 
1304-1311(2006).

24. Seo, Y. J., Cha, J. H., Lee, H., Ha, Y. J., Koh, J. H. and Lee, C. H., "P(VDF-HPF)-based Polymer Electrolyte Filled with Mesoporous ZnS,' Korean Chem. Eng. Res. (HWAHAK KONGHAK), 46(1), 170-174(2008).

25. Harris, C. S. and Rukavina, T. G., "Lithium Ion Conductors and Proton Conductors: Effects of Plasticizers and Hydration", Electrochim. Acta, 40(13-14), 2315-2320(1995).

26. Osaka, T., Liu, X., Nojima, M. and Mastuda, T., “An Electrochemical Double Layer Capacitor Using an Activated Carbon Electrode with Gel Electrolyte Binder,', J. Electrochem. Soc., 146, 1724-1729(1999).

27. Johan, M. R., Shy, O. H., Ibrahim, S., Yassin, S. M. M. and Hui, T. Y., "Effects of $\mathrm{Al}_{2} \mathrm{O}_{3}$ Nanofiller and EC Plasticizer on the Ionic Conductivity Enhancement of Solid PEO- $\mathrm{LiCF}_{3} \mathrm{SO}_{3}$ Solid Polymer Electrolyte," Solid State Ion., 196, 41-47(2011).

28. Kim, H. S., Cho, B. W., Yun, K. S. and Chun, H. S., "Electrochemical Characteristics and Physical Properties of Poly(ethylene oxide)-Li Based Polymer Electrolyte,' J. Korean Ind. Eng.
Chemistry, 7(3), 433-442(1996).

29. Wen, Z., Itoh, T., Ikeda, M., Hirata, N., Kubo, M. and Yamamoto, O., "Characterization of Composite Electrolytes Based on a Hyperbranched Polymer,' J. Power sources, 90(1), 20-26(2000).

30. Lin, C. W., Hung, L. C., Venkateswarlu, M. and Hwang, B. J., "Influence of $\mathrm{TiO}_{2}$ Nano-particles on the Transport Properties of Composite Polymer Electrolyte for Lithium-ion Batteries,' $J$. Power Sources, 146, 397-401(2005).

31. Wang, Y. J. and Kim, D. J., "Crystallinity, Morphology, Mechanical Properties and Conductivity Study of in Situ Formed PVDF/ $\mathrm{LiClO}_{4} / \mathrm{TiO}_{2}$ Nanocomposite Polymer Electrolytes,' Electrochimica Acta, 52, 3181-3189(2007).

32. Kim, S. and Park, S. J., "Preparation and Ion-conducting Behaviors of Poly(ethylene oxide)-composite Electrolytes Containing Lithium Montmorillonite,' Solid State Ion., 178, 973-979(2007).

33. Kim, S. and Park, S. J., "Interlayer Spacing Effect of Alkylammonium-modified Montmorillonite on Conducting and Mechanical Behaviors of Polymer Composite Electrolytes,' J. Colloid Interface Sci., 332, 145-150(2009). 